\title{
Transforming Organization through Instructional Leadership and Supervision (TOILS)
}

\author{
Jordan Tovera Salvador, PhD, RN \\ University of Dammam, Kingdom of Saudi Arabia \\ Sunshine Jade Tovera Salvador \\ University of Perpetual Help System DALTA, Las Pinas, Philippines
}

doi: 10.19044/esj.2016.v12n31p189 URL:http://dx.doi.org/10.19044/esj.2016.v12n31p189

\begin{abstract}
Instructional leadership and supervision has been subjected in different substantiations in terms of its theoretical standpoints and underpinnings. These are often defined similarly, however, these two have different definitions when it comes to some aspects in the operations within the organization. Instructional leadership involves activities in managing an educational facility, while, supervision is defined as the guidance and oversight of an expert or a more experienced person. In fact, it is usually related with continuous improvement and sustainable development in the classroom instructions. The principal being the head of the school must have a robust platform in leading and managing the educational facility. The main goal of this paper is to establish a concept of instructional leadership and supervision that would answer all the questions in maintaining high competency level of faculty members, sustaining effectiveness of teaching and learning, upholding maximum students' development programs and transforming the vision, voices, and values of the members of the organization towards solid vision, missions, objectives, and goals.
\end{abstract}

Keywords: Instructional Leadership, Integrated Development Model, Organization, Supervision, Transormation

\section{Introduction}

Instructional leadership and supervision has always have been subjected in various substantiations in terms of its theoretical standpoints and underpinnings (Sharma, 2012; Leighwood, 1994). Instructional leadership and supervision are often defined similarly, however, these two have different delineations when it comes to some aspects. Instructional leadership involves activities in managing an educational facility. In fact, it is usually related with continuous improvement and sustainable development in the 
classroom instructions. The principal being the head of the school must have a robust platform in leading and managing the educational facility. Bridges (1967) believed that of all the major responsibilities of the principals, curriculum and instructions have been the biggest challenges they faced in the educational services. This is the reason why experts believed that instructional leadership should be exercised in order to mitigate all the gaps. Instructional leadership is a 'must-have' for principals to effectively and efficiently manage the school tantamount in meeting the vision, mission, goal, and objectives of the institution.

The main goal of this paper is to establish a concept of instructional leadership and supervision that would answer all the questions in maintaining high competency level of faculty members, sustaining effectiveness of teaching and learning, upholding maximum students' development programs and transforming the vision, voices, and values of the members of the organization towards solid vision, missions, objectives, and goals. This paper apparently would like to seek the following specific objectives according to the various domains of learning:

1. Define instructional leadership and supervision (remember).

2. Abridge the related literature pertaining instructional and transformational leaderships, models of supervisions, etc. to understand the concept of this paper (understand).

3. Form a diagram that illustrates the framework of the new concept of instructional leadership and supervision in transforming the organization (apply).

4. Explore the various aspects concerning the transformation of the organization: structure, climate and culture, and situation (analyze).

5. Reflect on the new learning and challenges of the new concept (evaluate).

6. Formulate a conclusion regarding the new concept of instructional leadership and supervision (create).

Supervision is defined as the guidance and oversight of an expert or a more experienced person (Duff and Shahin, 2010). Technically speaking, supervision is part of management process, which is always partnered with leadership. Over the years, there are a lot of models of supervision were introduced; nevertheless, each model has loopholes that need to be addressed just like the 'master-apprentice model'. Falender \& Shafranske (2008) revealed that clinical knowledge and skills are not straightforwardly inherited. This means that an apprentice could not easily acquire competency by merely imitating, observing and shadowing his master. It needs additional theoretical activities that would guide the supervisee's reflection on the whole process of supervision as well as further training and development that would enhance his skills. Smith (2009) denoted that clinical supervision is 
multifarious give-and-take relationship of the supervisor and the supervisee, which is guided with models, theories and experiences in order to come up with a framework that a supervisee can use anytime soon. Consequently, in order to be a supervisor, a person must be competent to pass on his knowledge, skills and attitude to the supervisee.

Instructional leadership and supervision are essential components that would make or break an educational facility. In fact, according to Glickman, Gordon, \& Ross-Gordon (2001), the main function of the instructional supervision in the educational system is to come up with an effective and efficient educational action based from individual actions of instructional effectiveness. It is a known fact that instructions among innumerable fields play important role in the growth and development of the institution especially in any academic settings. The principal acts as the instructional supervisor and at the same time evaluate the faculty members for teaching effectiveness. Conversely, not all principals are effective instructional supervisors and at the same time have the tendency to be biased in the evaluation. The big question is, how can a principal be an efficient instructional supervisor and evaluator at the same time without compromising the job responsibilities of the same positions. Likewise, how can a principal uphold excellence in teaching, sustain students' development and promote high competency level of faculty members.

\section{Literature Review}

Transforming the organization towards the envisioned 'blueprint' is not an easy task for leaders and managers in all field types. It takes various assessment tools and methods, strategic planning, implementations and evaluations to discover the most suitable process running the organization to its sustainable development. The concept of this model is to transmute the vital components of the organization into catalysts for significant transformations with the employment of instructional leadership and supervision; thus, it appeals in achieving maximum prospective performances for both personal and professional development of students and faculty members.

The concept, likewise, is founded in the umbrellas of three known models of leadership and supervision: transformational leadership model (1978), instructional leadership model (2012) and developmental supervision model particularly from integrated development model or 'IDM' (1998). Transformational leadership was first introduced by Bernard Bass (1985) coining the work of James MacGregor Burns' (1978) 'transforming leadership'. This leadership model envisages the following aspects according to Bass (1985): accentuating intrinsic motivation of followers, moral standards awareness, prioritization, promoting moral maturity, 
creating harmonious relationship of members, providing mentoring and coaching, engaging to followers' appeals and upholding freedom of choices among its members. Likewise, leaders of this leadership style hold trust and confidence among the members of the organization that they will deliver the best outcomes.

Instructional leadership is notable for its connection with the management in educational system. Zepeda (2003) stated that instructional leadership is a critical aspect in maintaining, sustaining, and developing the educational facility. Instructional leaders, principals', should have a clear vision of the what would be the university should be accomplishing and achieving for specific period of time in terms of teaching and learning effectiveness, teachers and students development and maintaining good relationship with the stakeholders and community. A study conducted by Shalma (2012) concluded that Asian principals used instructional leadership as tools in learning, developing moral values and developing professional and personal aspects of each person in the educational facility. Instructional leadership, likewise, sets standard roles of the principal such as: (1) commitment for student's development (2) shared leadership, (3) supervisory leadership, and (4) continuous professional development for all (Sharma, 2012). She also explained that utilizing instructional leadership in the schools would entail positive outcomes leading to the 'overall development of the students and satisfaction of higher needs of recognition, self-esteem and self actualization of all' (Shalma, 2012, p. 20).

Integrated Development Model of Supervision (IDM) has a strong foundation to be an effective framework and platform for instructional supervision. The latest version of Stoltenberg, McNeill, and Delworth's Integrated Development Model of Supervision (1997), which had been popular due to its descriptive in the foundations of the supervisee per level of development and at same time discusses each level's prescriptive supervisory interventions that were lacking in the previous early developmental models, tried to alleviate the loopholes and shortcomings of the early development models of supervision. An anonymous author from the Adolescence journal stated that: 'Stoltenberg et al (1997) indicated in their book that IDM is a proven and adaptable model for supervising therapists at all levels of experience across disciplines and therapeutic orientations' (p. 185). IDM has four levels that a supervisee should partake and fulfill (Stoltenberg et al, 1998). These levels diverge from being a novice to master professional, thus, have distinctive skills and competencies that are discoverable along the process of supervision. A newly staff nurse hired in a hospital is a best-fit example for these levels. A staff nurse who just landed the job is considered to be a novice due to unfamiliarity in the bylaws, protocols, policies and procedures of the institution, nevertheless, training 
and development activities are provided to orient the staff nurse to blend in with the organization. Furthermore, IDM showcases a dynamical process of learning and development between the supervisor and supervisee, thus, achieving its goal to make the supervisee attain a status from novice to a master professional. The proponent of the IDM made sure that supervisors would have appropriate guidance through strategies, interventions, and methods of supervision that promotes continuous growth and development. Thus, it also explores on how to prevent and resolve diversity issues at all cost.

These three concepts will the theoretical foundations that will utilize in the new concept of instructional leadership and supervision in transforming the organization tantamount in achieving the vision, mission, goal and objectives of the institution.

\section{The New Concept of Instructional Leadership and Supervision}

This new concept is derived from the three drivers of instructional leadership and supervision namely transformational leadership, instructional leadership, and integrated development model (IDM). This concept is called Transforming Organization through Instructional Leadership and Supervision (TOILS). TOILS is designed not only for academia, nevertheless, all sort of field will be benefitting with this concept of leadership and supervision. It aims to transform the organization according to its vision, missions, goal and objectives through utilizing the aforementioned drivers of instructional leadership and supervision. The principal, being the person in achieving the success of the educational facility, should be the catalyst in transforming the faculty members and students to get involve in the effectiveness of teaching and learning programs and activities of the institution. Thus, this concept envisions that all members of the organization will have creative outlets in developing their personal and professional endeavors.

This concept has three main components: supervisor, faculty members and students. The supervisor, a principal or the head of the department, plays a vital role in this process. He acts as the catalyst for transformation particularly leading into achievement of growth and development when it comes to teaching and learning as well as the professional endeavors of the faculty members and students. Through utilization of instructional leadership and integrated development model of supervision, the supervisor role is to act as the instructional supervisor to his subordinates particularly those who just entered the educational facility. Supervision depends on the level of competency of the supervisee specifically on the knowledge and skills. The supervisor will continuously assess and evaluate the supervisee and provide information on how to 
effectively work on the areas for improvement. Reflection of the process of supervision should be a mandatory activity throughout the course. The supervisor constantly provides insight and discernments based from personal and professional experiences that the supervisee may use and serve as a foundation in putting up his own ideologies into actions. Thus, the entire process transforms the novice supervisee into a competent and proficient professional.

The instructional leader's role includes vast commitment to the overall development of the faculty members and students, spearheads the educational facility with shared and supervisory leadership styles, and plans for continuous professional development for the members of the organization.

The main goal of the TOILS is to yield an organizational transformation based from the following efforts of the supervisor: (1) vision, mission, goal and objectives, (2) commitment to service and (3) transformational, shared and supervisory leadership. Other outcomes of TOILS centralize on the following aspects: students (learning development, students' achievement and extra and co-curricular activities) and faculty members (personal and professional development, level of competency and career growth). This concept utilizes the three components of the organization (structure, climate and culture, and development) in sustaining the high standards of teaching and learning effectiveness and medium of instructions set by the institution, and satisfaction of higher needs of acknowledgement, self-confidence and self actualization of all members of the organization.

The role of supervision in instructional leadership is largely managing the curriculum and instructions of an educational facility (Marks and Printy, 2003). Conversely, supervision does not only pertain to its aforementioned function, however, as a supervisor, he or she looks the organization, both faculty members and students, as a whole or as a system. Instructional supervisors must create clear visions of what should be expected for the people (structure), behavior (climate and culture), and situation (development). These three components should be intertwined to that would result transformation for the whole organization.

The figure below shows the diagram of this particular concept, Transforming Organization through Instructional Leadership and Supervision (TOILS): 


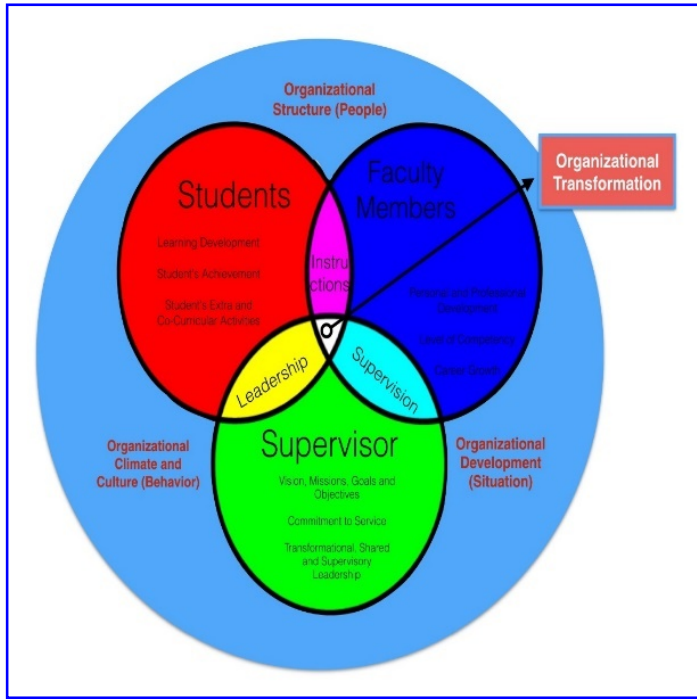

Figure 1: Transforming Organization through Instructional Leadership and Supervision (TOILS)

\section{Implications, New Learning and Challenges of the New Concept in Transforming the Organization}

This concept can be applicable not only for educational facility but other fields as well that requires leadership and management and direct supervision. TOILS will be most successful in staff orientations, clinical placements and supervisions and staff training and development as well as teaching and learning activities for students' development.

In terms of new learning, TOILS is a product of three drivers of instructional leadership and supervision, likewise, creating and formulating new concepts based from previous models and theories may be permissible and viable conforming to the assessed needs of a particular organization. Instructional leadership and supervision have so many models and frameworks that can serve as foundations in establishing new concepts that may be applicable in various fields.

Challenges of TOILS may be seen particularly in the implementation phase of the process due to the meticulous and systematized assessment and planning, which includes establishing the vision, missions, goal, and objectives. Instructional supervisors must keep in mind that the main goal of the concept is to transform the organization for the better. Personal gains and advantages should be excluded in the formula to prevent any conflicts. Moreover, Shared and supervisory leadership styles should be exercised to work keep the process smoothly flowing and according to the goal of the concept. Continuous assessment and evaluation should be done for monitoring purposes. 


\section{Conclusion}

Transforming Organization through Instructional Leadership and Supervision (TOILS) is a concept derived from transformational leadership model (1986), instructional leadership model (2012) and developmental supervision model particularly from integrated development model or 'IDM' (1998), which has the capacity to be an effective framework for instructional supervision (Salvador, 2016). The concept is designed not only for academia, nevertheless, all sort of field will be benefitting with this concept of leadership and supervision. The main goal of this concept is to transform all the components of the organization namely structure (people), climate and culture (behavior) and development (situation) would work together to produce positive outcomes that would benefit all the members of the organization, likewise, transform into better versions of themselves.

\section{References:}

1. Bridges, E. (1967). Instructional leadership: A concept reexamined. Journal of Educational Administration, 5(2), 136-147.

2. Duff, C., \& Shahin, J. (2010). Conflict in Clinical Supervision: Antecedents, Impact, Amelioration, and Prevention. Alberta Counselor, 31, 1, 3-8.

3. Falender, C. A., \& Shafranske, E. P. (2004). Clinical supervision: A competency-based approach. Washington, DC: American Psychological Association.

4. Glickman, C. D., Gordon, S. P., \& Ross-Gordon, J. M. (2001). Supervision and instructional leadership (5th ed.). Needham Heights, MA: Allyn \& Bacon.

5. Leithwood, K. \& Jantzi, D. (1999). The relative effects of principal and teachers sources of leadership on student is school. Educational Administration Quarterly, 35, 679-706. ís-i

6. Salvador, J. T. (2016). Integrated Development Model (IMD): A Systematic Review and Reflection. European Scientific Journal, ESJ, 12(19).

7. Sharma, S. (2012). Instructional Leadership Model through Asian Principals’ Perspectives. International Conference on Education and Management Innovation IPEDR vol.30. IACSIT Press, Singapore.

8. Smith, K. (2009). A Brief Summary of Supervision Models.

9. Stoltenberg, C. D., McNeill, B., \& Delworth, U. (1998). IDM supervision: An integrated developmental model for supervising counselors and therapists. SanFrancisco: Jossey-Bass.

10. Zepeda, S. (2003) The Principal as an Instructional Leader: a handbook of Supervision. Eye on Education, New York. iَ' 